\title{
OPEN A mild aqueous synthesis of ligand-free copper nanoparticles for low temperature sintering nanopastes with nickel salt assistance
}

\begin{abstract}
Hiroshi Imamura ${ }^{1,2 \bowtie}$, Yoichi Kamikoriyama ${ }^{2}$, Atsushi Muramatsu ${ }^{1}$ \& Kiyoshi Kanie ${ }^{1 \bowtie}$
An organic ligand-free aqueous-phase synthesis of copper (Cu) nanoparticles (NPs) under an air atmosphere was successfully achieved by reducing copper(II) oxide particles with a leaf-like shape in the presence of Ni salts at room temperature. The resulting Cu NPs with a mean particle diameter of $c a .150 \mathrm{~nm}$ exhibited low-temperature sintering properties due to their polycrystalline internal structure and ligand-free surface. These Cu NPs were applied to obtain Cu NP-based nanopastes with low-temperature sintering properties, and the resistivities of the obtained Cu electrodes after annealing at $150^{\circ} \mathrm{C}$ and $200^{\circ} \mathrm{C}$ for $30 \mathrm{~min}$ were $64 \mu \Omega \cdot \mathrm{cm}$ and $27 \mu \Omega \cdot \mathrm{cm}$, respectively. The bonding strength between oxygen-free $\mathrm{Cu}$ plates prepared using the Cu NP-based nanopastes reached $32 \mathrm{MPa}$ after pressure-less sintering at $260^{\circ} \mathrm{C}$ for $30 \mathrm{~min}$ under a nitrogen atmosphere. The developed manufacturing processes using the developed $\mathrm{Cu}$ nanopastes could provide sustainable and low- $\mathrm{CO}_{2}-$ emission approaches to obtain Cu electrodes on flexible films and high-strength bonding between metal plates as die-attach materials for power devices under energy- and resource-saving conditions.
\end{abstract}

Printed electronics (PE) technology has attracted a great deal of attention as one of the most promising manufacturing techniques for items such as electronic, mobile, and wearable future devices under low energy consumption and low carbon dioxide emission conditions; this technology is appealing because the electronic circuits and semiconductor layers in the devices are directly fabricated on the device substrates through a successive printing process under atmospheric conditions ${ }^{1-3}$. In PE technology, nano- and micron-sized metal particle inks and pastes are widely used to prepare conductive patterns on electronic circuit boards ${ }^{4-8}$. In particular, silver particle-based inks and pastes are the most representative and useful due to their advantageous characteristics, such as low resistivity, low-temperature sinterability, and high antioxidation ability ${ }^{9}$. Recently, these advantages have been applied in the combination of PE and integrated circuit (IC) production technologies, namely, flexible hybrid electronics (FHE) technology $y^{10-12}$. This technology enables us to fabricate flexible devices on plastic films with low thermal resistivity through an on-demand and eco-friendly process. To date, various types of future devices, such as wearable devices, have been developed and demonstrated based on market needs. Silver particle-based pastes have also recently received considerable attention as die-attach materials for the fabrication of next-generation $\mathrm{SiC}$ - and $\mathrm{GaN}$-based power devices ${ }^{13,14}$. The larger bandgaps of SiC- and GaN-based power semiconductor materials than the corresponding Si-based materials enable device operation above $200{ }^{\circ} \mathrm{C}$, which could permit miniaturization of the power modules. Furthermore, the high energy efficiency of hightemperature-driven power semiconductors is also quite suitable for the electrification of vehicles and is desirable for a future carbon-neutral society. As conventional die-attach materials, solder alloys have been widely used for Si-based device manufacturing. However, the low melting point and low thermal conductivity of solder alloys ${ }^{15}$ are becoming potential problems for die-attach materials from a viewpoint of application to high-temperaturedriven $\mathrm{SiC}$ - and $\mathrm{GaN}$-based power semiconductors ${ }^{16}$. To overcome these problems, low-temperature-sintered silver particle-based pastes with high thermal stability and high thermal conductivity have attracted much attention as promising candidates for die-attach materials applicable to SiC- and GaN-based device manufacturing.

${ }^{1}$ Institute of Multidisciplinary Research for Advanced Materials, Tohoku University, Sendai 980-8577, Japan. ${ }^{2}$ Business Creation Sector R\&D Center, Mitsui Mining \& Smelting Co., Ltd., Ageo 362-0021, Japan. ${ }^{\square}$ email: hi_imamura@mitsui-kinzoku.com; kanie@tohoku.ac.jp 
Although practical applications of silver particle-based inks and pastes are now rapidly progressing in PE, FHE, and power device technologies, fundamental problems of silver, such as its high cost as a precious metal and propensity for electromigration, inducing short circuits, are probably inescapable. More recently, copper $(\mathrm{Cu})$ particle-based inks and pastes have rapidly been considered as candidates to solve silver-related problems in $\mathrm{PE}, \mathrm{FHE}$, and power device technologies because $\mathrm{Cu}$ is an inexpensive metal, has high electronic conductivity $(1.68 \mu \Omega \cdot \mathrm{cm})$ and high thermal conductivity $(398 \mathrm{~W} / \mathrm{m} \cdot \mathrm{K})$ values equivalent to those of silver and exhibits less electron migration than silver ${ }^{17,18}$. To date, liquid-phase synthesis of $\mathrm{Cu}$ nanoparticles (NPs) for ink and paste applications has been carried out in organic solvents in the presence of organic ligands to control the size and to prevent oxidation and aggregation of the $\mathrm{Cu} \mathrm{NPs}{ }^{19,20}$. However, synthesizing $\mathrm{Cu}$ NPs at a low cost on an industrial scale for practical applications is potentially problematic because the usage of organic solvents and organic ligands results in waste disposal issues. Furthermore, organic ligands, such as polymers and surfactants, remain on the surfaces of the particles, increasing the resistivity of the particles, and high-temperature treatment above $300{ }^{\circ} \mathrm{C}$ is required to remove these ligands from the surfaces of the particles to improve the resistivity and progress of sintering ${ }^{21}$. Such high-temperature sintering processes are difficult to apply in PE and FHE technologies because the flexible plastics used as substrates exhibit low thermal resistance ${ }^{2}$. Additionally, the development of a low-temperature die-attach process is desirable not only to reduce thermal damage to power semiconductor chips but also to save energy and resources. To date, photonic ${ }^{22,23}$, plasmatic ${ }^{24}$, and reducing atmospheric sintering ${ }^{25,26}$ have also been considered. However, these processes require expensive apparatuses and are not suitable for mass production on an industrial scale. To overcome this fundamental problem, Cu NPs with low-temperature sintering properties are desired, and such $\mathrm{Cu}$ NPs have recently been prepared by aqueous or polyol solvent systems in the presence of low-molecular-weight organic compounds ${ }^{27-30}$. Deng et al. ${ }^{27}$ reported that single nanosized $\mathrm{Cu}$ NPs were obtained in water in the presence of a large amount of glycolic acid or lactic acid. The resulting $\mathrm{Cu}$ NP-coated films exhibited values of $25.5 \pm 8.0 \mu \Omega \cdot \mathrm{cm}$ (glycolic acid) and $21.0 \pm 7.0$ $\mu \Omega \cdot \mathrm{cm}$ (lactic acid) after sintering at $150^{\circ} \mathrm{C}$ under a $\mathrm{N}_{2}$ atmosphere. The utilization of organic amines with low boiling points has also been studied for $\mathrm{Cu}$ NP synthesis. Hokita et al. ${ }^{28}$ observed that the resistivity of 1-amino2-propanol-modified $\mathrm{Cu} N$ Ps reached $30 \mu \Omega \cdot \mathrm{cm}$ after sintering at $150{ }^{\circ} \mathrm{C}$ under a $\mathrm{N}_{2}$ atmosphere. Mou et al. ${ }^{29}$ also applied 1-amino-2-propanol-modified $\mathrm{Cu}$ NPs to prepare a die-attach material for $\mathrm{Cu}$-Cu bonding, and the shear and bonding strength reached $23 \mathrm{MPa}$ upon heating at $200{ }^{\circ} \mathrm{C}$ under an argon atmosphere with $5 \mathrm{MPa}$ pressure. The above described techniques enabled the development of low-temperature fabrication processes; however, a low oxidation resistance and low storage stability are fundamental problems for practical applications of these $\mathrm{Cu}$ NP-based pastes. More recently, we reported that polycrystalline Cu NPs were successfully obtained by reducing an aqueous copper(II)-nitrilotriacetic acid complex in a mild water system. The corresponding $\mathrm{Cu}$ nanopastes exhibited remarkable low-temperature sintering behaviour and high antioxidation properties and was applied to both fabricating electric circuits on flexible films and binding model IC chips on Cu substrates as power modules ${ }^{30}$. The process temperature was lower than $200^{\circ} \mathrm{C}$; however, it is difficult to further decrease the sintering temperature because the value strongly depends on the decomposition temperature of the organic compounds used for Cu NP synthesis. Furthermore, gas generation by the degradation of organic compounds by thermal treatment leads to a reduction in the electronic properties and bonding reliability of Cu electrodes and bonding materials because gas formation causes the formation of voids and cracks in the materials. In addition, using organic chemicals such as carboxylic acids and amines increases the manufacturing costs for Cu NPs.

Towards future material innovation in PE, FHE, and die-attach material technologies for a carbon-neutral society, the development of synthetic procedures for low-temperature sintering of $\mathrm{Cu}$ NPs without using organic chemicals has become an important issue to be resolved. Organic compounds are widely utilized to control the size and shape of NPs as well as to prevent the coagulation of $\mathrm{NPs}^{31-34}$. In this regard, a new concept to realize the size control of $\mathrm{Cu}$ NPs without the use of organic chemicals is urgently required. We focused on the addition of base transition metal salts for size control of $\mathrm{Cu}$ NPs because inorganic salts sometimes affect the size and shape of the resulting NPs ${ }^{35,36}$. The utilization of noble metal NPs is well known to accelerate heterogeneous nucleation to induce NP formation and growth ${ }^{37-39}$. However, using noble metals increases manufacturing costs. In this study, we report the aqueous-phase ambient synthesis of Cu NPs with low-temperature sinterability by the reduction of copper(II) oxide $(\mathrm{CuO})$ particles with a leaf-like morphology in the presence of base transition metal salts without any usage of organic chemicals. The resulting $\mathrm{Cu}$ NPs were used to prepare a $\mathrm{Cu}$ NP-based nanopastes applicable not only for the fabrication of $\mathrm{Cu}$ electric circuits on flexible films but also as a die-attach material for the fabrication of next-generation power devices under mild sintering conditions, such as pressureless and $\mathrm{N}_{2}$ atmosphere conditions.

\section{Results and discussion}

Preparation of CuO particles with a leaf-like shape for Cu NP synthesis. In liquid-phase synthetic systems of inorganic NPs based on nucleation followed by particle growth, the particle size can be controlled by complexation of the precursors with organic ligands because the initial nucleation number determining the final mean particle size obeys the solubility product of the resulting complexes in the system ${ }^{40}$. However, another method should be considered under organic ligand-free systems. In our previous studies, monodispersed copper(I) oxide $\left(\mathrm{Cu}_{2} \mathrm{O}\right)$ particles were successfully obtained by using $\mathrm{CuO}$ solid particles with a leaf-like morphology as the precursor in the presence of gelatine as an anti-aggregation agent ${ }^{41}$. The leaf-like shape with a wide specific surface area accelerates the dissolution rate of the $\mathrm{CuO}$ particles into the solvent; supersaturation and rapid nucleation are reached in a short period, resulting in highly monodispersed $\mathrm{Cu}_{2} \mathrm{O}$ particles. Kobayashi et al. also reported the synthesis of $\mathrm{Cu}$ particles using $\mathrm{CuO}$ solid particles as a raw material in cetyltrimethylammonium bromide (CTAB) aqueous solution ${ }^{42}$. In this case, a decrease in the mean particle diameter of the resulting $\mathrm{Cu}$ NPs was observed due to decreasing the particle size of the $\mathrm{CuO}$ precursors. This behaviour is also 

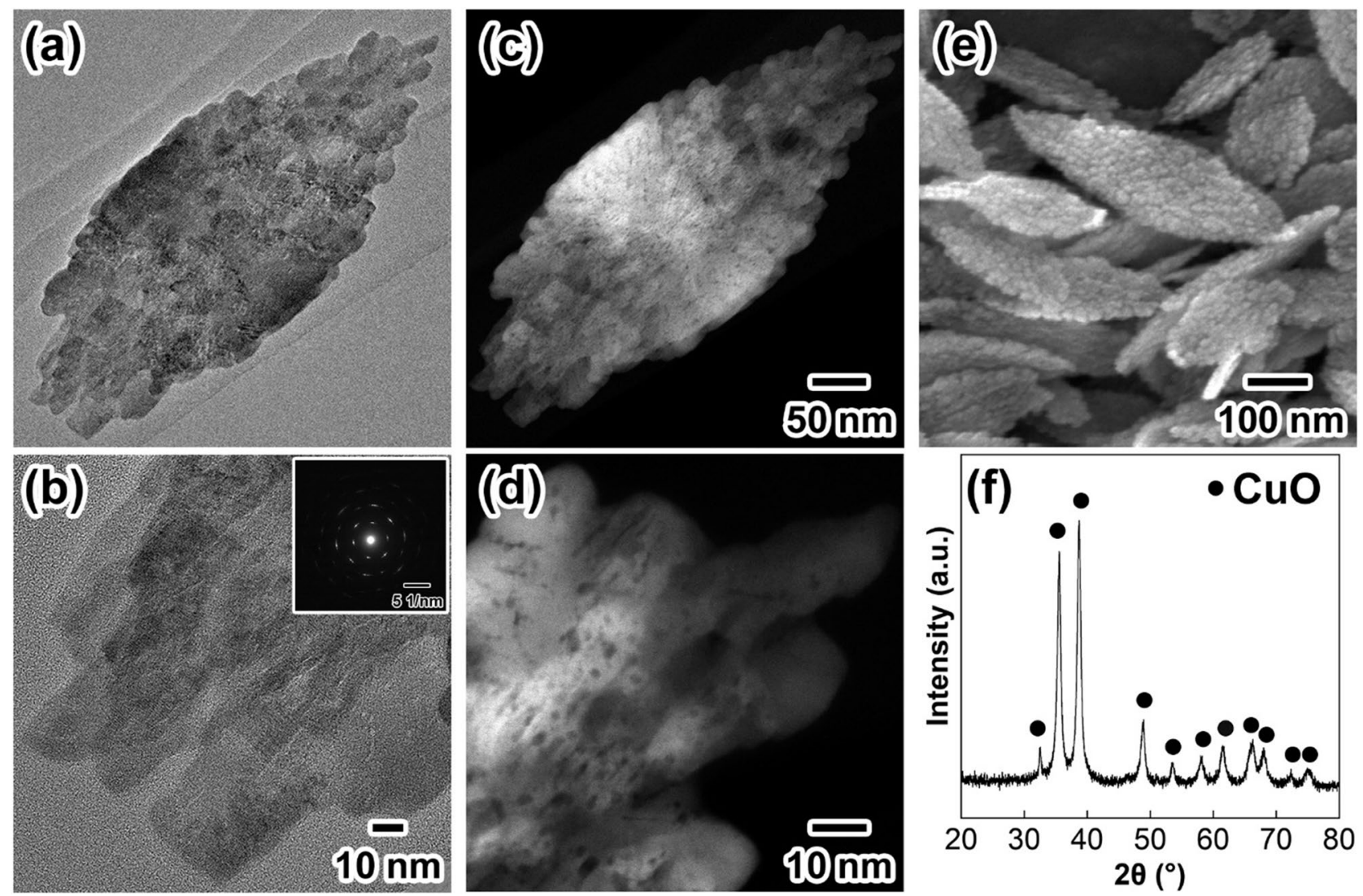

Figure 1. Results of characterization of $\mathrm{CuO}$ particles with a leaf-like shape as a solid precursor for $\mathrm{Cu} \mathrm{NP}$ synthesis. (a) HR-TEM image; (b) magnified image of (a). The inset is the FT image of (b); (c) HAADF-STEM image; (d) magnified image of (c); (e) FE-SEM image; (f) XRD profile of the solid powder. The scale bar in (b) is the same as that for $(\mathbf{a})$.

probably due to acceleration of the dissolution rate of the $\mathrm{CuO}$ precursors into the solvent by the size-dependent increase in the specific surface area of the $\mathrm{CuO}$ precursors. These previous studies suggested that utilization of solid precursors is a promising technique for ligand-free liquid-phase syntheses of NPs because controlling the dissolution rate of the solid precursors by controlling their shape and size leads to precise size control of purpose-designed NPs. In the present study, we focused on $\mathrm{CuO}$ solid particles ${ }^{42}$ with a leaf-like shape and therefore a large specific surface area as a raw material for the ligand-free synthesis of $\mathrm{Cu}$ NPs. The purpose-designed $\mathrm{CuO}$ particles were prepared as follows: initially, an aqueous light blue-coloured suspension of copper(II) hydroxides, which was obtained by mixing $5.0 \mathrm{~L}$ of $0.40 \mathrm{M} \mathrm{Cu}\left(\mathrm{NO}_{3}\right)_{2}$ and $5.0 \mathrm{~L}$ of $0.80 \mathrm{M} \mathrm{NaOH}$ aqueous solutions at room temperature, was aged at $40{ }^{\circ} \mathrm{C}$ for $8 \mathrm{~h}$ under atmospheric conditions. The solid particles thus obtained were filtered, washed with water, and dried at $120^{\circ} \mathrm{C}$ prior to use for the present $\mathrm{Cu}$ NP synthesis.

Figure 1 summarizes the characterization results for the solid particles used as the precursor for the preparation of $\mathrm{Cu}$ NPs. From the high-resolution transmission electron microscopy (HR-TEM) images shown in Fig. 1a,b, the particles consist of leaf-like shapes with a rough surface and internal voids. Similar polycrystalline images are also seen in the high-angle annular dark field scanning TEM (HAADF-STEM) images (Fig. 1c,d). The corresponding field emission scanning electron microscopy (FE-SEM) image in Fig. 1e reveals that the leafshaped particles have a major axis of $420 \pm 89 \mathrm{~nm}$, a minor axis of $245 \pm 66 \mathrm{~nm}$, and a thickness of several tens of $\mathrm{nm}$. Small protrusions with a size of several tens of nm were observed on the surfaces of the particles in the SEM image. From the X-ray diffraction (XRD) pattern shown in Fig. 1f, all the diffraction peaks could be assigned to the formation of a single $\mathrm{CuO}$ crystal phase (JCPDS: 041-0254). The average crystallite size of the particles was calculated as $15 \mathrm{~nm}$ using Scherrer's equation ${ }^{43}$ (Scherrer constant: 1.33), which was in good agreement with the primary particle size on the surface of the $\mathrm{CuO}$ particles in Fig. 1f. The results suggested that the $\mathrm{CuO}$ particles basically consist of a polycrystalline crystal structure. The inset in Fig. 1b presents a Fourier transform (FT) image of Fig. 1b. Highly oriented diffraction spots attributed to a single crystalline structure are visible in the FT images. These results mean that $\mathrm{CuO}$ particles with a polycrystalline structure were obtained through epitaxial growth of nuclei on the surface to produce primary particles with a crystallite size of $c a .15 \mathrm{~nm}$. The specific surface area of the resulting polycrystalline particles was $22 \mathrm{~m}^{2} / \mathrm{g}$, as determined by $\mathrm{N}_{2}$ adsorption measurements.

Mild aqueous-phase synthesis of Cu NPs under organic ligand-free conditions by nickel salt assistance. As mentioned above, the addition of anti-aggregation agents such as gelatine ${ }^{41}$ and $\mathrm{CTAB}^{42}$ is a practical way to obtain highly monodispersed NPs. To establish an organic ligand-free liquid-phase synthetic 
(a)

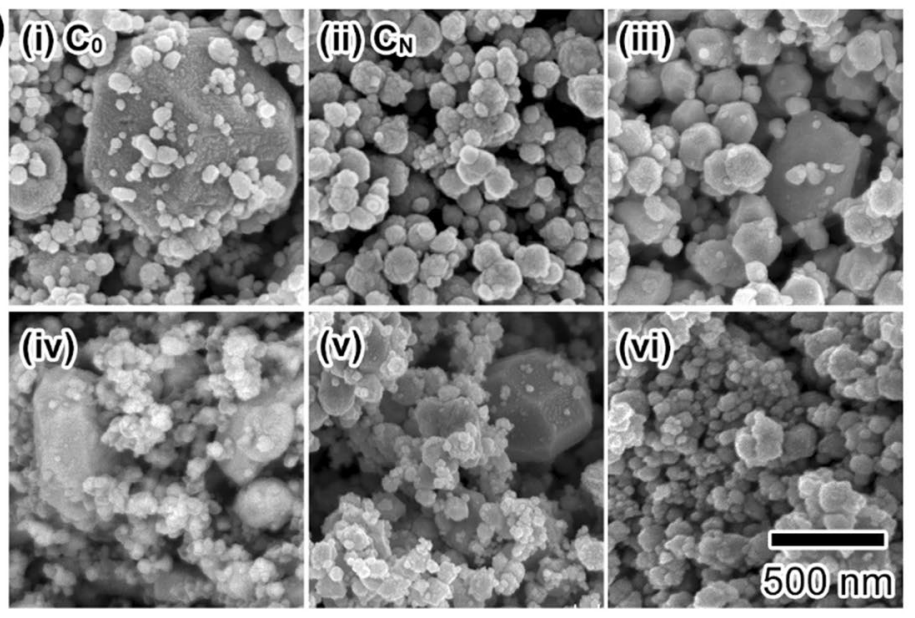

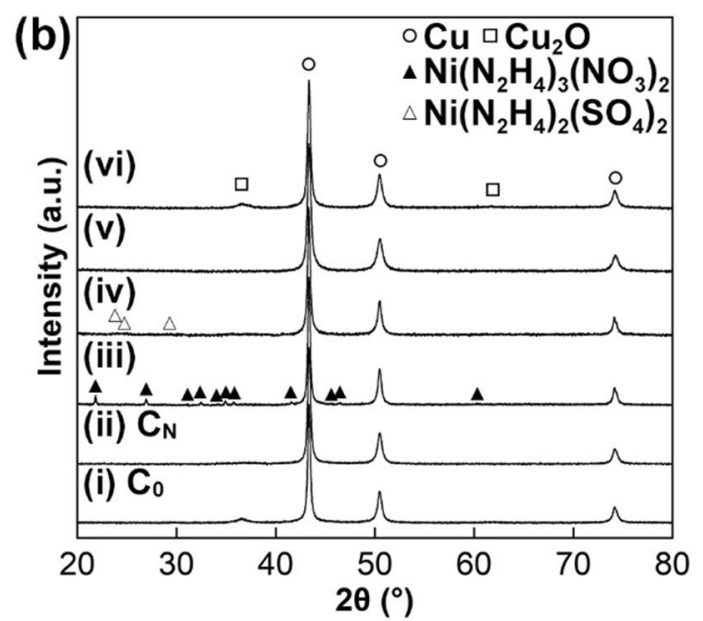

Figure 2. Results of morphological observation by FE-SEM and crystal structure analysis of Cu NPs by XRD. (a) FE-SEM images and (b) XRD patterns of the solid particles. (i): [Ni salt] $/[\mathrm{CuO}]=0, \mathbf{C}_{\mathbf{0}}$; (ii): $\left[\mathrm{NiCl}_{2}\right] /$ $[\mathrm{CuO}]=0.10, \mathrm{C}_{\mathrm{N}} ;(\mathrm{iii}):\left[\mathrm{Ni}\left(\mathrm{NO}_{3}\right)_{2}\right] /[\mathrm{CuO}]=0.10$; (iv): $\left[\mathrm{NiSO}_{4}\right] /[\mathrm{CuO}]=0.10 ;(\mathrm{v}):\left[\mathrm{NiCl}_{2}\right] /[\mathrm{CuO}]=0.050 ;(\mathrm{vi})$ : $\left[\mathrm{NiCl}_{2}\right] /[\mathrm{CuO}]=0.20$. The scale bar shown in (a)-(vi) is common to all images in (a).

method, we applied water-soluble base transition metal salts during particle growth. The representative procedure for the preparation of $\mathrm{Cu}$ NPs in the presence of base transition metal salts is as follows: Initially, CuO particles $(6.12 \mathrm{mmol}, 0.487 \mathrm{~g})$ with a leaf-like shape, $\mathrm{NiCl}_{2} \cdot 6 \mathrm{H}_{2} \mathrm{O}(0.61 \mathrm{mmol}, 0.148 \mathrm{~g})$, and ion-exchanged water $(20 \mathrm{~mL})$ were mixed in a beaker $(50 \mathrm{~mL})$ with stirring $(250 \mathrm{rpm})$ at room temperature under an air atmosphere. Then, an aqueous solution of hydrazine monohydrate $(4.85 \mathrm{~mol} / \mathrm{L}, 5.0 \mathrm{~mL})$ was added in one portion to the mixture in the beaker with stirring $(300 \mathrm{rpm})$ at room temperature. The resulting mixture was stirred for $2 \mathrm{~h}$ under the same conditions. The brown-coloured solids were collected by filtration using a cellulose acetate membrane filter with a pore size of $0.45 \mu \mathrm{m}$. The resulting solids were washed with ion-exchanged water until the conductivity of the filtrate became lower than $0.1 \mathrm{mS} / \mathrm{cm}$. Finally, the collected solids were washed three times with denatured alcohol by centrifugation $(10,000 \mathrm{G}, 10 \mathrm{~min})$ and dried under a reduced atmosphere to obtain $\mathrm{Cu}$ NPs. Further details of the synthetic procedure are summarized in the Methods section.

Effects of nickel salt species and concentration on Cu NP synthesis. Initially, we investigated the effects of nickel salt species on the size and shape of the resulting $\mathrm{Cu}$ NPs. Figure 2a-i exhibits an FE-SEM image of the solid particles obtained without the use of nickel salts (abbreviated as $\mathbf{C}_{\mathbf{0}}$ ). Figure 2a-ii-iv show FESEM images of as-prepared particles in the presence of nickel chloride $\left(\mathrm{NiCl}_{2}\right)$, nickel nitrate $\left(\mathrm{Ni}\left(\mathrm{NO}_{3}\right)_{2}\right)$, and nickel sulfate $\left(\mathrm{NiSO}_{4}\right)$, respectively. Here, the mixing molar ratio of $\mathrm{Ni}$ salts to $\mathrm{CuO}$ was fixed to 0.10 ([Ni salt]/ $[\mathrm{CuO}]=0.10$ ). Both highly crystalline large particles with flat crystal planes (particle size: $c a .1 \mu \mathrm{m}$ ) and small NPs with an irregular shape (mean particle size: $144 \pm 59 \mathrm{~nm}$ ) were obtained when Cu NP synthesis was carried out without the use of Ni salts (Fig. 2a-i). In contrast, no highly crystalline particles were seen in the solid particles prepared in the presence of $\mathrm{NiCl}_{2}$ (Fig. 2a-ii), which are abbreviated as $\mathbf{C}_{\mathbf{N}}$. This result suggests that $\mathrm{NiCl}_{2}$ has a positive effect on preventing the formation of highly crystalline large particles during the synthesis of $\mathrm{Cu}$ NPs starting from $\mathrm{CuO}$. The effects of $\mathrm{Ni}\left(\mathrm{NO}_{3}\right)_{2}$ and $\mathrm{NiSO}_{4}$ on $\mathrm{Cu} \mathrm{NP}$ synthesis were lower than that of $\mathrm{NiCl}_{2}$ because some highly crystalline large particles were clearly seen in Fig. 2a-iii,iv. The average particle sizes of the NPs, except for the large particles with flat crystal planes, obtained with $\mathrm{NiCl}_{2}, \mathrm{Ni}\left(\mathrm{NO}_{3}\right)_{2}$, and $\mathrm{NiSO}_{4}$ were $156 \pm 48 \mathrm{~nm}, 209 \pm 45 \mathrm{~nm}$ and $173 \pm 77 \mathrm{~nm}$, respectively. The particle size was determined by counting more than 200 NPs in the corresponding SEM images. Figure 2b shows XRD patterns of as-prepared particles in the absence or presence of nickel salts. The main diffraction peaks at $43.34^{\circ}, 50.48^{\circ}$, and $74.14^{\circ}$ could be assigned to the formation of a $\mathrm{Cu}$ metal phase as the main phase in the solid particles. The crystallite sizes of the $\mathrm{Cu}$ NPs obtained in the presence of $\mathrm{NiCl}_{2}, \mathrm{Ni}\left(\mathrm{NO}_{3}\right)_{2}$, and $\mathrm{NiSO}_{4}$ were calculated as $28 \mathrm{~nm}, 31 \mathrm{~nm}$, and $39 \mathrm{~nm}$, respectively ${ }^{43}$. The crystallite size was much smaller than the average particle size, indicating that the Cu NPs have a polycrystalline structure. Broad diffraction peaks due to a $\mathrm{Cu}_{2} \mathrm{O}$ phase in Fig. $2 \mathrm{~b}$ suggest partial surface oxidation of the $\mathrm{Cu}$ NPs during purification. Similar behaviour was also observed in our previous study ${ }^{30}$. As shown in Fig. 2b-iii,iv, the formation of nickel hydrazine solid complexes was observed with the use of $\mathrm{Ni}\left(\mathrm{NO}_{3}\right)_{2}$ and $\mathrm{NiSO}_{4}$. Precipitation of such solid complexes is the most plausible reason why the effects of $\mathrm{Ni}\left(\mathrm{NO}_{3}\right)_{2}$ and $\mathrm{NiSO}_{4}$ on the prevention of highly crystalline large particles are lower than that of $\mathrm{NiCl}_{2}$ in the preparation of $\mathrm{C}_{\mathrm{N}}$.

$\mathrm{Next}$, we also tested the effect of the concentration of $\mathrm{NiCl}_{2}$ on $\mathrm{Cu} \mathrm{NP}$ synthesis. Figure $2 \mathrm{a}-\mathrm{v}$, vi show FESEM images and XRD patterns of as-prepared $\mathrm{Cu}$ NPs with different $\left[\mathrm{NiCl}_{2}\right] /[\mathrm{CuO}]$ ratios of 0.050 and 0.20 , respectively. The average $\mathrm{Cu}$ particle sizes of the samples were $246 \mathrm{~nm}$ and $123 \mathrm{~nm}$. In the case of $\left[\mathrm{NiCl}_{2}\right] /$ $[\mathrm{CuO}]=0.050$, highly crystalline large particles with flat surfaces (approximately $500 \mathrm{~nm}$ ) were observed in the SEM images (Fig. 2a-v). No such particles were observed in the sample produced at $\left[\mathrm{NiCl}_{2}\right] /[\mathrm{CuO}]=0.10: \mathbf{C}_{\mathrm{N}}$ and 0.20 . The mean particle size of the $\mathrm{Cu}$ NPs decreased with increasing $\mathrm{NiCl}_{2}$ concentration. This result suggests that $\mathrm{NiCl}_{2}$ not only prevents the production of highly crystalline particles but also accelerates nucleation to 

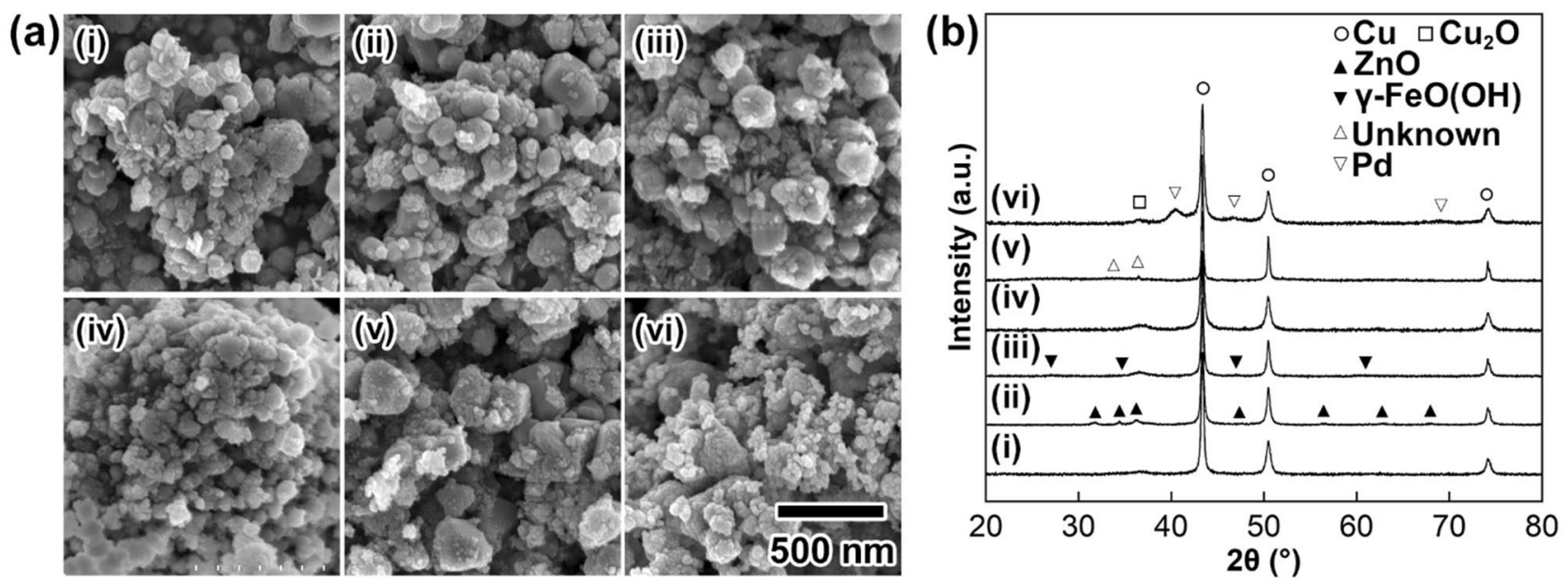

Figure 3. Morphological observation and crystal structure analysis of $\mathrm{Cu}$ NPs. (a) FE-SEM images and (b) XRD patterns of solid particles formed by changing the metal salt species: (i) $\mathrm{CoCl}_{2}$; (ii) $\mathrm{ZnCl}_{2}$; (iii) $\mathrm{FeCl}_{2}$; (iv) $\mathrm{TiCl}_{4}$; (v) $\mathrm{SnCl}_{4}$; (vi) $\mathrm{PdCl}_{2}$. The ratio of [metal salts]/[CuO] was fixed to 0.10 . The scale bar shown in (a)-(vi) is the same for all images in (a).

obtain polycrystalline $\mathrm{Cu}$ NPs with small sizes. Such effects of $\mathrm{NiCl}_{2}$ on $\mathrm{Cu} \mathrm{NP}$ synthesis might be largely due to a change in the reducing rate of $\mathrm{N}_{2} \mathrm{H}_{4}$ by complexation to form water-soluble $\mathrm{NiCl}_{2}-\mathrm{N}_{2} \mathrm{H}_{4}$ complexes to accelerate the nucleation number of $\mathrm{Cu}$ in the growth solutions. A change in colour from light green to light purple just after the addition of $\mathrm{N}_{2} \mathrm{H}_{4}$ to the $\mathrm{NiCl}_{2}$ aqueous solutions, suggesting complexation, was observed in the case of precipitation. Further mechanistic characterizations aiming to accelerate nucleation to obtain $\mathrm{Cu}$ NPs with the addition of $\mathrm{NiCl}_{2}$ are now in progress and will be reported elsewhere by the authors.

Effect of metal salt species on Cu NP synthesis. Figure 3 exhibits the (a) FE-SEM images and (b) XRD profiles of solid particles obtained by adding (i) cobalt(II) chloride $\left(\mathrm{CoCl}_{2}\right)$, (ii) zinc chloride $\left(\mathrm{ZnCl}_{2}\right)$, (iii) iron(II) chloride $\left(\mathrm{FeCl}_{2}\right.$ ), (iv) titanium chloride $\left(\mathrm{TiCl}_{4}\right)$, (v) tin(IV) chloride $\left(\mathrm{SnCl}_{4}\right)$, and (vi) palladium(II) chloride $\left(\mathrm{PdCl}_{2}\right)$, instead of $\mathrm{NiCl}_{2}$, in the current $\mathrm{Cu} \mathrm{NP}$ synthesis. All the synthetic conditions were the same as those for $\mathbf{C}_{\mathbf{N}}$ except for the metal species. The [metal salt]/[CuO] ratio was fixed to 0.10 for all cases. The standard electrode reduction potentials of these metals are in the following order: palladium: $0.95 \mathrm{~V}$; copper: $0.34 \mathrm{~V}$; tin: $-0.14 \mathrm{~V}$; nickel: $-0.26 \mathrm{~V}$; cobalt: $-0.28 \mathrm{~V}$; iron: $-0.76 \mathrm{~V}$; zinc: $-0.76 \mathrm{~V}$; titanium: $-1.63 \mathrm{~V}^{44}$. As shown in Fig. 3a-i-vi, the evolution of highly crystalline large particles with flat crystal planes, similar to those seen in Fig. 1a-i, was inhibited by the usage of metal chlorides. The addition of metal salts provably prevents uniform crystal growth, allowing the formation of highly crystalline $\mathrm{Cu}$ particles in the growth solutions. XRD measurements revealed that all the solid particles had a $\mathrm{Cu}$ metal phase as the main phase (Fig. 3b). The crystallite sizes of the $\mathrm{Cu}$ NPs in Fig. 3b-i-v were calculated as $30.8 \mathrm{~nm}, 38.8 \mathrm{~nm}, 43.9 \mathrm{~nm}, 25.3 \mathrm{~nm}$, and $64.7 \mathrm{~nm}$, respectively ${ }^{43}$. The crystallite sizes were smaller than the mean particle sizes and indicated polycrystalline structures for all particles. From the XRD profiles in Fig. 3b-ii,iii,v, $\mathrm{ZnO}, \gamma$-FeOOH, and an unknown phase, respectively, contaminated the solid phases. Furthermore, amorphous-like precipitates attributable to titanium hydroxides are clearly seen in Fig. 3a-iv. Formation of these solid by-products in $\mathrm{Cu}$ NPs results in an increase in the resistivity of the material. When $\mathrm{PdCl}_{2}$ was used for the synthesis, a palladium metal phase was clearly observed (Fig. 3bvi). The NPs a single nanometre in size in Fig. 3a-vi are considered palladium metal NPs. The higher redox potential of palladium than copper resulted in the formation of both palladium and copper metal NPs. These results suggested that the addition of metal chlorides such as $\mathrm{NiCl}_{2}$ and $\mathrm{CoCl}_{2}$ has a positive effect on obtaining $\mathrm{Cu}$ NPs for the synthesis of ligand-free $\mathrm{Cu}$ NPs applicable for Cu NP-based nanopastes with low-temperature sintering ability.

Effects of reducing agents on Cu NP synthesis. Figure 4a,b-i-iv show FE-SEM images and XRD patterns of solid particles obtained with different $\mathrm{N}_{2} \mathrm{H}_{4}$ concentrations $\left(\left[\mathrm{N}_{2} \mathrm{H}_{4}\right] /[\mathrm{CuO}]\right.$ : (i) 1.0 ; (ii) 2.0 ; $\mathrm{C}_{\mathrm{N}} 4.0$; (iii) 8.0; (iv) 16). When $\left[\mathrm{N}_{2} \mathrm{H}_{4}\right] /[\mathrm{CuO}]$ was adjusted to 1.0 , the reducing reaction for the formation of Cu NPs did not proceed perfectly, and the $\mathrm{CuO}$ phase used as the precursor was observed as the main phase (Fig. 3i). Upon increasing the $\left[\mathrm{N}_{2} \mathrm{H}_{4}\right] /[\mathrm{CuO}]$ ratio from 2.0 to 16 , Cu NPs were formed in a single phase, and the mean particle size decreased with increasing $\mathrm{N}_{2} \mathrm{H}_{4}$ concentration. Figure $4 \mathrm{v}$,vi show (a) FE-SEM images and (b) XRD patterns of solid particles obtained by using sodium borohydride $\left(\mathrm{NaBH}_{4}\right)$ and $\mathrm{L}-(+)$-ascorbic acid (AA) as reducing agents with [reducing agent] $/[\mathrm{CuO}]=4.0$. Some leaf-like particles assigned as $\mathrm{Cu}$ NPs are seen in Fig. 4a-v, suggesting that direct reduction from $\mathrm{CuO}$ particles with a leaf-like shape to corresponding $\mathrm{Cu}$ particles proceeded by using $\mathrm{NaBH}_{4}$. From the XRD profile in Fig. $4 \mathrm{~b}-\mathrm{v}$, the crystallite size of the $\mathrm{Cu}$ particles was $15 \mathrm{~nm}$, which further supported the direct reduction of the $\mathrm{CuO}$ particles because the crystallite size of the $\mathrm{CuO}$ particles was also $15 \mathrm{~nm}$. This behaviour is probably due to the higher reduction ability of $\mathrm{NaBH}_{4}$ than $\mathrm{N}_{2} \mathrm{H}_{4}$. When AA was used as the reducing agent, Cu NPs with a cubic shape were obtained as the main product (Fig. $4 \mathrm{vi})$. The crys- 

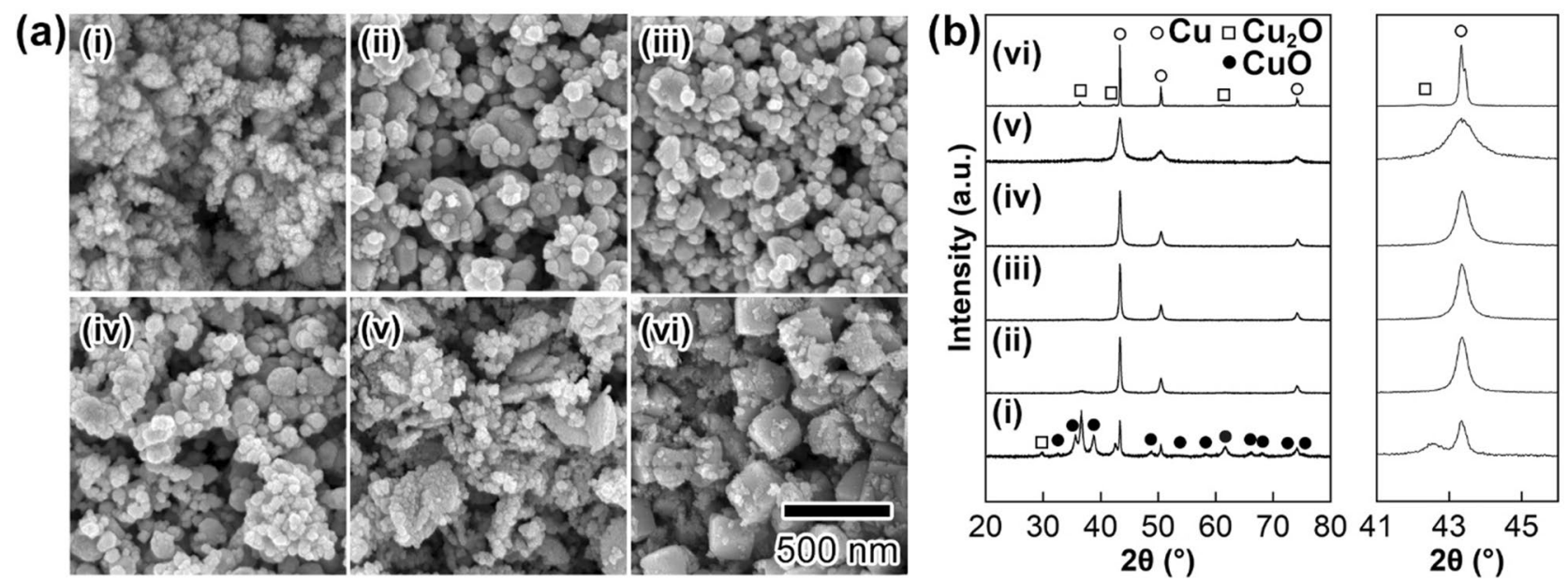

Figure 4. Results of (a) FE-SEM observations and (b) XRD measurements of solid particles formed by various ratios of [reducing agents]/[CuO]. Hydrazine, sodium borohydride $\left(\mathrm{NaBH}_{4}\right)$, and ascorbic acid (AA) were chosen as the reducing agents. (i) $\left[\mathrm{N}_{2} \mathrm{H}_{4}\right] /[\mathrm{CuO}]: 1.0$; (ii) $\left[\mathrm{N}_{2} \mathrm{H}_{4}\right] /[\mathrm{CuO}]: 2.0$; (iii) $\left[\mathrm{N}_{2} \mathrm{H}_{4}\right] /[\mathrm{CuO}]: 8.0$; (iv) $\left[\mathrm{N}_{2} \mathrm{H}_{4}\right] /[\mathrm{CuO}]: 16$; (v) $\left[\mathrm{NaBH}_{4}\right] /[\mathrm{CuO}]: 4.0$; (vi) [AA]/[CuO]: 4.0; The scale bar shown in (a)-(vi) is common for all images in (a).
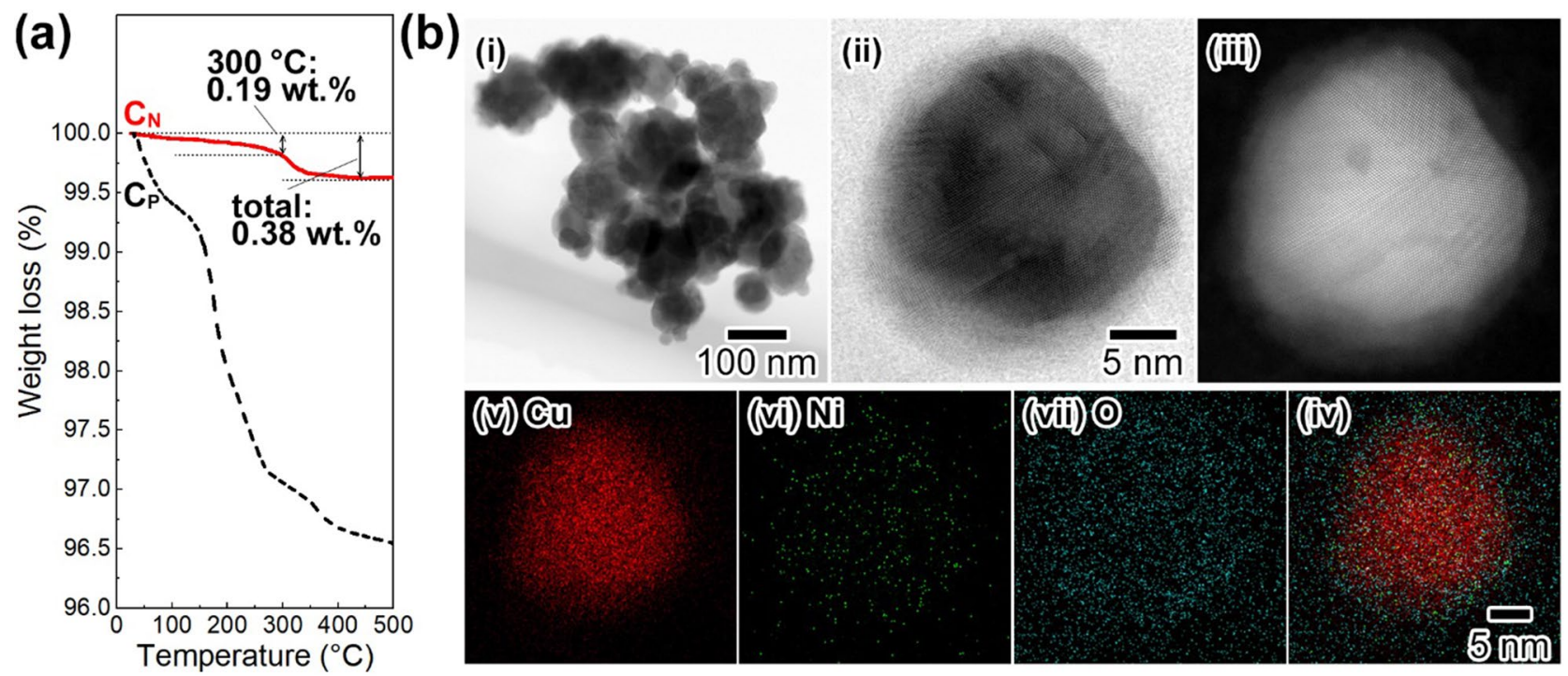

Figure 5. Results of characterization of $\mathbf{C}_{\mathbf{N}}$. (a) TG profiles of $\mathbf{C}_{\mathbf{N}}$ (a solid line) and $\mathbf{C}_{\mathbf{P}}{ }^{30}$ (a dashed line). (b) (i) TEM image; (ii) HR-TEM image; (iii) HAADF-STEM image of the EDS analysis area. EDS images of (iv) copper $K_{\alpha 1} ;(v)$ nickel $K_{\alpha 1}$; (vi) oxygen $K_{\alpha 1}$. (vii) Merged image of (iv-vi).

tallite size of $91.3 \mathrm{~nm}$, calculated by using the XRD profile shown in Fig. 4b-vi, is similar to the corresponding mean particle size of the $\mathrm{Cu}$ nanocubes. It can be considered that the lower reduction ability of AA than $\mathrm{N}_{2} \mathrm{H}_{4}$ leads to the formation of single-crystalline $\mathrm{Cu}$ nanocubes by slow and uniform particle growth in the solvent. As described above for the optimization of the reaction conditions, we could conclude that $\mathrm{NiCl}_{2}$ and $\mathrm{N}_{2} \mathrm{H}_{4}$ are the most suitable compounds for Ni salt-assisted $\mathrm{Cu}$ NP synthesis for the development of Cu NP-based nanopastes with low-temperature sintering properties.

Characterization of the surface and internal structures of $\mathbf{C}_{\mathbf{N}}$. Figure 5 a shows thermogravimetric (TG) profiles of $\mathbf{C}_{\mathbf{N}}$ and our previously prepared $\mathrm{Cu}$ NPs using nitrilotriacetic acid $\left(\mathbf{C}_{\mathbf{p}}\right)^{30}$. Interestingly, the weight loss of $\mathbf{C}_{\mathbf{N}}$ up to $300{ }^{\circ} \mathrm{C}$ was only $0.19 \mathrm{wt} \%$. Upon further heating, a $0.38 \mathrm{wt} \%$ weight loss was observed at approximately $310^{\circ} \mathrm{C}$ for $\mathrm{C}_{\mathrm{N}}$, which is due to decomposition of a $\mathrm{Cu}_{2} \mathrm{O}$ phase on the surface of $\mathrm{C}_{\mathrm{N}}$. In contrast, the weight loss of $\mathrm{C}_{\mathrm{P}}$ up to $300^{\circ} \mathrm{C}$ was $2.9 \mathrm{wt} \%$. The loss is due to degradation of organic residues on the surface of $\mathbf{C}_{\mathbf{p}}$. Such degradation has a potential problem to lead to gas generation in the preparation of $\mathrm{Cu}$ electrodes and adhesion of IC chips with the usage of $\mathrm{Cu}$ NP-based nanopastes. From this point of view, the present $\mathbf{C}_{\mathrm{N}}$ obtained under $\mathrm{Ni}$ salt-assisted ligand-free conditions has a large potential for application in Cu NP-based nanopastes with minimal gas evolution. Figure $5 \mathrm{~b}$ shows the observed internal structures and surface states of $\mathbf{C}_{\mathrm{N}}$ obtained by TEM and HAADF-STEM equipped with an energy dispersive X-ray spectroscopy (EDS) system. The poly- 

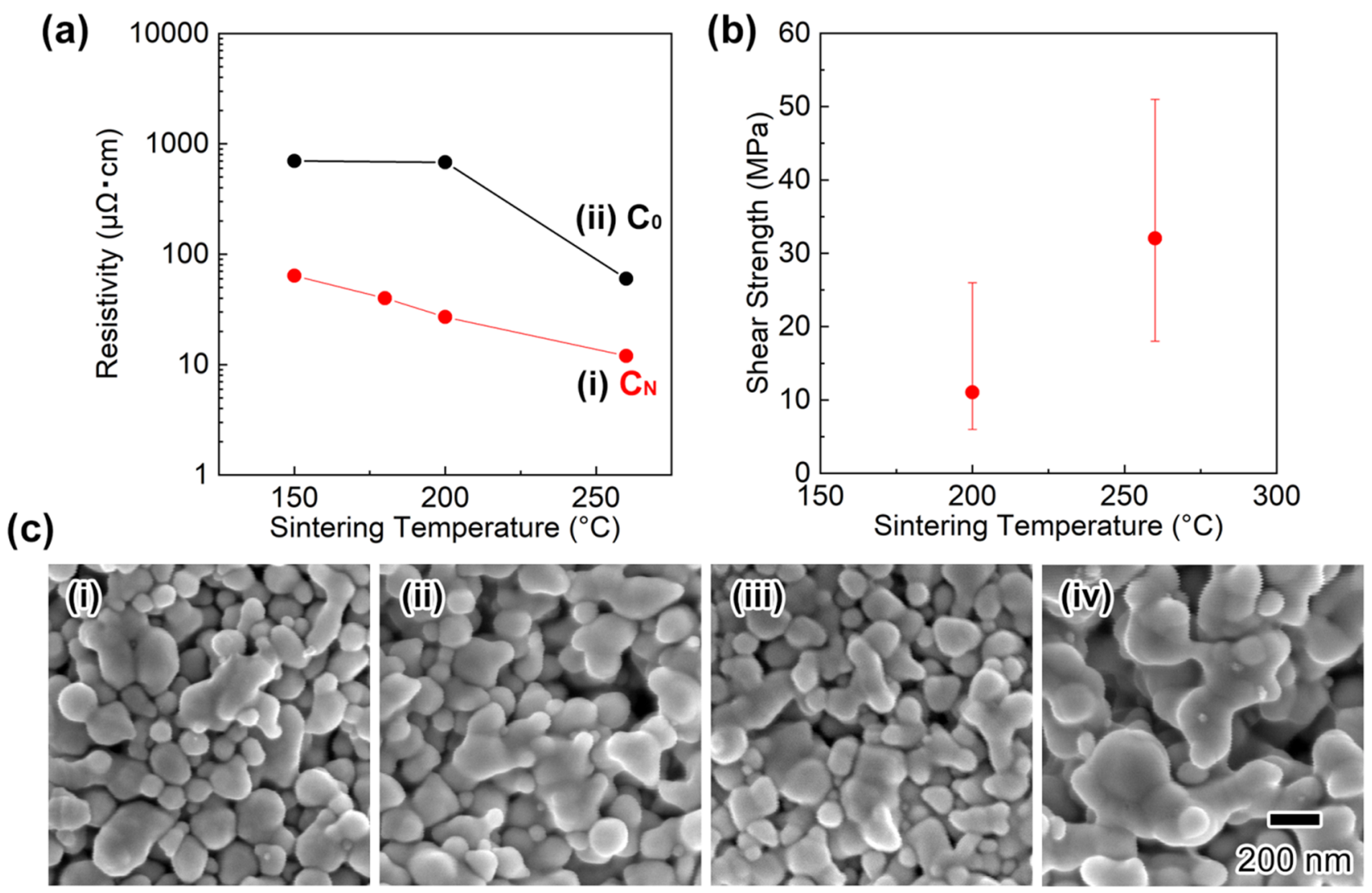

Figure 6. Sintering behaviour of the NP paste and characterization of sintering films. (a) Resistivity of sintering films at different temperatures made from pastes of copper particles synthesized with different molar ratios of $\left[\mathrm{NiCl}_{2}\right] /[\mathrm{Cu}]$ (i): 0.1 (Ni-salt-assisted method), (ii): 0. (b) Shear strength of NP pastes obtained at different temperatures by pressure-less sintering under a $\mathrm{N}_{2}$ atmosphere. (c) SEM images of $\mathrm{Cu}$ sintering films made from nanopastes on a glass substrate sintered at (i) $150^{\circ} \mathrm{C}$, (ii) $180^{\circ} \mathrm{C}$, (iii) $200^{\circ} \mathrm{C}$, and (iv) $260^{\circ} \mathrm{C}$ under a $\mathrm{N}_{2}$ atmosphere for $30 \mathrm{~min}$.

crystalline crystal structure of $\mathbf{C}_{\mathrm{N}}$ is clearly seen in the TEM image in Fig. 5b-i. The HR-TEM image suggests the existence of a rough shell structure on the surface of $\mathbf{C}_{\mathrm{N}}$ with a thickness of $c a .3 \mathrm{~nm}$ (Fig. 5b-ii). From the XRD profile of $\mathbf{C}_{\mathbf{N}}$ in Fig. $2 \mathrm{~b}$-ii, $\mathrm{C}_{\mathbf{N}}$ contains a $\mathrm{Cu}_{2} \mathrm{O}$ phase. This result means that the shell consists of a $\mathrm{Cu}_{2} \mathrm{O}$ phase due to the partial surface oxidation of $\mathbf{C}_{\mathbf{N}}$ during the purification process. Figure $5 b$-iii is the HAADF-STEM image of $\mathbf{C}_{\mathbf{N}}$. The corresponding EDS mapping patterns of copper, nickel, and oxygen and the merged image are seen in Fig. 5b-iv-vii, respectively. These images suggest that $\mathrm{Ni}$ atoms are incorporated and uniformly distributed in $\mathrm{C}_{\mathrm{N}}$ and oxygen atoms are distributed on the surface of $\mathbf{C}_{\mathrm{N}}$ to form the $\mathrm{Cu}_{2} \mathrm{O}$ shell layer. X-ray photoelectron spectroscopy (XPS) revealed that $\mathrm{Ni}$ species on the surface of $\mathrm{Cu}$ particles exist mainly as oxides. The polycrystalline core-shell structure of $\mathbf{C}_{\mathrm{N}}$ provides a low sintering temperature, high oxidation resistance, and long-term stability.

Sintering behaviour of Cu NP-based pastes. Figure 6a summarizes the resistivity of $\mathrm{Cu}$ electrodes fabricated by using $\mathrm{Cu}$ NP-based nanopastes with different sintering temperatures. (i) $\mathbf{C}_{\mathrm{N}}$ and (ii) $\mathbf{C}_{0}$ were chosen as the $\mathrm{Cu}$ NPs to evaluate the effect of $\mathrm{Ni}$ salt assistance on the sintering and electric properties. The resulting resistivities of $\mathrm{Cu}$ electrodes fabricated with $\mathrm{C}_{\mathrm{N}}$-based nanopastes at sintering temperatures of $150{ }^{\circ} \mathrm{C}, 180^{\circ} \mathrm{C}$, $200{ }^{\circ} \mathrm{C}$, and $260^{\circ} \mathrm{C}$ were $64 \mu \Omega \cdot \mathrm{cm}, 40 \mu \Omega \cdot \mathrm{cm}, 27 \mu \Omega \cdot \mathrm{cm}$, and $12 \mu \Omega \cdot \mathrm{cm}$, respectively, which were lower than those of $\mathbf{C}_{0}$-based electrodes (cf. the resistivities of electrodes sintered at $150{ }^{\circ} \mathrm{C}, 200{ }^{\circ} \mathrm{C}$, and $260{ }^{\circ} \mathrm{C}$ were 700 $\mu \Omega \cdot \mathrm{cm}, 681 \mu \Omega \cdot \mathrm{cm}$, and $60 \mu \Omega \cdot \mathrm{cm}$, respectively). Figure $6 \mathrm{~b}$ exhibits the shear strength of $\mathrm{Cu}-\mathrm{Cu}$ bonded bodies, representing a model IC chip, adhered by using the $\mathbf{C}_{\mathbf{N}}$-based nanopastes under pressure-less and $\mathrm{N}_{2}$ atmospheric conditions. The details for the preparation of the model IC chips are summarized in the Methods section below. The shear strengths after sintering at $200^{\circ} \mathrm{C}$ and $260^{\circ} \mathrm{C}$ for $30 \mathrm{~min}$ were $11 \mathrm{MPa}$ and $32 \mathrm{MPa}$, respectively. A shear strength greater than $30 \mathrm{MPa}$ at $260^{\circ} \mathrm{C}$ under pressure-less conditions is suitable for practical applications to produce power devices ${ }^{30}$. Figure $6 \mathrm{c}$ shows FE-SEM images of sintered Cu electrodes prepared by using the $\mathbf{C}_{\mathrm{N}}$-based nanopastes. From the images, sintering between $\mathbf{C}_{\mathrm{N}}$ NPs and the formation of necking structures was already underway at $150^{\circ} \mathrm{C}$, and the growth of necking structures proceeded upon increasing the sintering temperature from 150 to $260^{\circ} \mathrm{C}$ (Fig. $6 \mathrm{c}$-i-iv). The crystallite sizes of the $\mathrm{Cu}$ electrodes after sintering at $150{ }^{\circ} \mathrm{C}$, $180^{\circ} \mathrm{C}, 200^{\circ} \mathrm{C}$, and $260^{\circ} \mathrm{C}$ were $41.5,47.1,55.5$, and $69.4 \mathrm{~nm}$, as determined by XRD measurements. The tough 

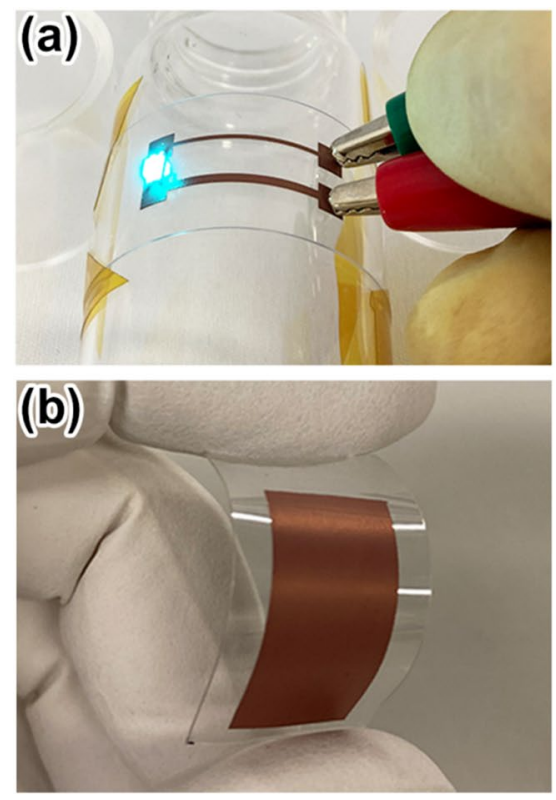

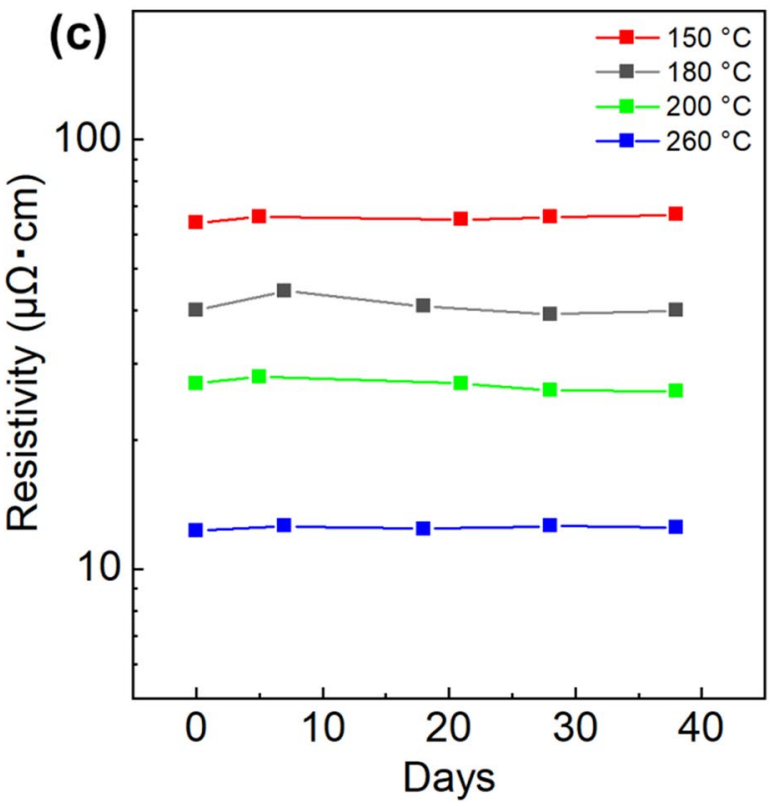

Figure 7. Characteristics of copper electrode formation on flexible substrates and stability of the copper electrode. (a) LED-mounted Cu electrode obtained by printing $\mathbf{C}_{\mathbf{N}}$ NP-based nanopastes on a PEN film and the LED emission behaviour. The device was prepared by sintering at $200{ }^{\circ} \mathrm{C}$ under a $\mathrm{N}_{2}$ atmosphere for $30 \mathrm{~min}$. (b) A $\mathrm{C}_{\mathrm{N}}$ NP-based electrode on a PET film obtained after sintering at $150^{\circ} \mathrm{C}$ under a $\mathrm{N}_{2}$ atmosphere for $30 \mathrm{~min}$. (c) Time changes in the resistivity of $\mathrm{Cu}$ electrodes obtained by sintering at $150{ }^{\circ} \mathrm{C}, 180{ }^{\circ} \mathrm{C}, 200{ }^{\circ} \mathrm{C}$, and $260{ }^{\circ} \mathrm{C}$ under a $\mathrm{N}_{2}$ atmosphere for $30 \mathrm{~min}$. The $\mathrm{Cu}$ electrodes on a glass substrate were kept under ambient atmospheric conditions at $24 \pm 1{ }^{\circ} \mathrm{C}$ and $44 \pm 1 \%$ humidity, and the resulting resistivities were measured for the stability test.

$\mathrm{Cu}-\mathrm{Cu}$ bonding is due to the sintering process between $\mathrm{Cu}$ NPs and associated formation of necking structures under mild conditions.

Preparation of copper electrodes on flexible films from Cu NP-based nanopastes. Figure 7a,b show photographs of $\mathrm{Cu}$ electrodes on a polyethylene naphthalate (PEN) film and a polyethylene terephthalate (PET) film, respectively, prepared by using $\mathbf{C}_{\mathrm{N}}$ NP-based nanopastes. The sintering temperatures for Fig. 7a,b were $150{ }^{\circ} \mathrm{C}$ and $200{ }^{\circ} \mathrm{C}$, respectively. Details for the preparation are summarized in the Methods section. No cracks were seen after repeated bending of the $\mathrm{Cu}$ electrode printed flexible films, and a simple light emission diode (LED) device on a PEN film was readily obtained. Figure $7 \mathrm{c}$ shows the results of stability testing of the $\mathrm{Cu}$ electrodes prepared by sintering at $150{ }^{\circ} \mathrm{C}, 180{ }^{\circ} \mathrm{C}, 200{ }^{\circ} \mathrm{C}$, and $260{ }^{\circ} \mathrm{C}$ under a $\mathrm{N}_{2}$ atmosphere for $30 \mathrm{~min}$. After preparation of the $\mathrm{Cu}$ electrodes on a PEN film, the electrodes were left under atmospheric conditions at a temperature of $24 \pm 1{ }^{\circ} \mathrm{C}$ and humidity of $44 \pm 1 \%$ for the stability test. Regardless of the sintering temperature, the resistance of the $\mathrm{Cu}$ electrodes remained almost unchanged for more than one month.

\section{Conclusions}

In the present study, we have established an organic ligand-free aqueous-phase synthesis of Cu NPs that are applicable for use in $\mathrm{Cu}$ NP-based nanopastes with low-temperature sintering properties. Here, the addition of $\mathrm{NiCl}_{2}$ played a critical role in reducing $\mathrm{CuO}$ solid particles with a leaf-like shape by hydrazine to obtain $\mathbf{C}_{\mathrm{N}}$ from an aqueous phase under ambient atmospheric conditions. Interestingly, the weight loss of $\mathbf{C}_{\mathbf{N}}$ due to organic residues on its surface was only $0.19 \mathrm{wt} \%$, as determined from TG-DTA measurements. The results suggested that $\mathrm{C}_{\mathrm{N}}$ with an organic ligand-free surface obtained by Ni salt assistance is a promising material for the development of $\mathrm{Cu}$ NP-based nanopastes with minimal gas evolution during $\mathrm{Cu}$ electrode fabrication and $\mathrm{Cu}-\mathrm{Cu}$ adhesion. Such gas formation is a serious problem in PE and FHE technologies and leads to the generation of cracks and voids, which reduce the quality and durability of the products. Due to the unique polycrystalline core-shell structure of $\mathbf{C}_{\mathbf{N}}$, determined by XRD, TEM, and HAADF-STEM characterizations, $\mathbf{C}_{\mathbf{N}}$ NP-based nanopastes with low-temperature sintering and antioxidation properties under atmospheric conditions were successfully obtained and applied for the fabrication of $\mathrm{Cu}$ electrodes on flexible films. The resistivity of $\mathrm{Cu}$ electrodes on a flexible film reached $64 \mu \Omega \cdot \mathrm{cm}$ and $27 \mu \Omega \cdot \mathrm{cm}$ after sintering at $150^{\circ} \mathrm{C}$ and $200{ }^{\circ} \mathrm{C}$, respectively. Furthermore, as a model of IC chip adhesion, the formation of $\mathrm{Cu}-\mathrm{Cu}$ bonded bodies with a high shear strength of $32 \mathrm{MPa}$ was achieved with the use of the $\mathrm{Cu}$ NP-based nanopastes after pressure-less sintering under a nitrogen atmosphere. The present $\mathrm{Cu}$ NP-based nanopastes are a promising material for achieving sustainable progress in PE, FHE and power device technologies and are expected to be applied in next-generation on-demand fabrication processes ${ }^{45}$ for future smart products, such as wearable devices, under energy- and resource-saving conditions. 


\section{Method}

Reagents. Unless otherwise noted, all reagents were used as received without further purification. Water was doubly distilled, deionized, and filtered prior to use. Copper nitrate trihydrate $\left(\mathrm{Cu}\left(\mathrm{NO}_{3}\right)_{2} \cdot 3 \mathrm{H}_{2} \mathrm{O}\right.$, Cat. No: 037-12505), sodium hydroxide $\left(\mathrm{NaOH}\right.$, Cat. No: 194-18865), nickel chloride hexahydrate $\left(\mathrm{NiCl}_{2} \cdot 6 \mathrm{H}_{2} \mathrm{O}\right.$, Cat. No: 141-01045), nickel nitrate hexahydrate $\left(\mathrm{Ni}\left(\mathrm{NO}_{3}\right)_{2} \cdot 6 \mathrm{H}_{2} \mathrm{O}\right.$, Cat. No: 147-01101), nickel sulfate hexahydrate $\left(\mathrm{NiSO}_{4} \cdot 6 \mathrm{H}_{2} \mathrm{O}\right.$, Cat. No: 146-01171), cobalt chloride hexahydrate $\left(\mathrm{CoCl}_{2} \cdot 6 \mathrm{H}_{2} \mathrm{O}\right.$, Cat. No: 036-03682), zinc chloride $\left(\mathrm{ZnCl}_{2}\right.$, Cat. No: 263-00271), iron chloride tetrahydrate $\left(\mathrm{FeCl}_{2} \cdot 4 \mathrm{H}_{2} \mathrm{O}\right.$, Cat. No: 099-00915), titanium chloride $\left(\mathrm{TiCl}_{4}\right.$, Cat. No: 202-12592), palladium(II) sodium chloride trihydrate $\left(\mathrm{PdCl}_{2} \cdot 2 \mathrm{NaCl} \cdot 3 \mathrm{H}_{2} \mathrm{O}\right.$, Cat. No: $\left.167-00081\right)$, sodium tetrahydroborate $\left(\mathrm{NaBH}_{4}\right.$, Cat. No: 195-11455), and L-(+)-ascorbic acid $\left(\mathrm{C}_{6} \mathrm{H}_{8} \mathrm{O}_{6}\right.$, Cat. No: 016-04,805) were purchased from FUJIFILM Wako Pure Chemical Corporation. Tin chloride $\left(\mathrm{SnCl}_{4}\right.$, anhydrous, Cat. No: 37312-01), hydrazine monohydrate $\left(\mathrm{N}_{2} \mathrm{H}_{4} \cdot \mathrm{H}_{2} \mathrm{O}\right.$, Cat. No: 18383-00), triethanolamine $\left(\mathrm{N}_{(}\left(\mathrm{CH}_{2} \mathrm{CH}_{2} \mathrm{OH}\right)_{3}\right.$, Cat. No: 40268-08), and dehydrated methanol ( $\mathrm{CH}_{3} \mathrm{OH}$, Cat. No: 25506-25) were purchased from Kanto Chemical Co., Inc. 3-Glycidoxypropyltrimethoxysilane (Cat. No: KBM-403) was purchased from Shin-Etsu Chemical Co., Ltd. Denatured alcohol was purchased from IMAZU CHEMICAL Co. Ltd.

Preparation of CuO particles as a precursor for Cu NP synthesis. Initially, $0.40 \mathrm{M} \mathrm{Cu}\left(\mathrm{NO}_{3}\right)_{2}(5.0$ $\mathrm{L})$ and $0.80 \mathrm{M} \mathrm{NaOH}(5.0 \mathrm{~L})$ aqueous solutions were mixed together at room temperature with stirring. Then, the resulting slurry was further stirred at $40^{\circ} \mathrm{C}$ for $8 \mathrm{~h}$. During this stage, the colour of the slurry changed from light blue to brown. The brown-coloured solids thus obtained were collected by filtration and washed with ionexchanged water by centrifugation $(20,000 \mathrm{G}, 30 \mathrm{~min})$ until the conductivity of the supernatant liquid became lower than $0.1 \mathrm{mS} / \mathrm{cm}$. Finally, the solids were dried at $120^{\circ} \mathrm{C}$ in a fine oven to obtain $\mathrm{CuO}$ particles with a leaflike shape.

Metal salt-assisted liquid-phase synthesis of Cu NPs. Self-prepared $\mathrm{CuO}$ particles with a leaf-like shape $(6.12 \mathrm{mmol}, 0.477 \mathrm{~g})$, metal salts $(0.61 \mathrm{mmol})$, and ion-exchanged water $(20 \mathrm{~mL})$ were added to a beaker and mixed with stirring $(250 \mathrm{rpm})$ at room temperature under an air atmosphere. Then, an aqueous solution of $4.85 \mathrm{M}$ hydrazine monohydrate $(24.3 \mathrm{mmol}, 5.0 \mathrm{~mL})$ was added to the mixture in the beaker in one portion with stirring $(250 \mathrm{rpm})$ at room temperature. The mixture was stirred for $2 \mathrm{~h}$ under the same conditions. The resulting solid particles were collected by filtration using a cellulose acetate membrane filter (pore size: $0.45 \mu \mathrm{m}$ ) and washed with deionized water until the conductivity of the filtrate was under $0.1 \mathrm{mS} / \mathrm{cm}$. Then, the particles were washed three times with denatured alcohol by dispersal and centrifugation (10,000 G, $10 \mathrm{~min})$, and the $\mathrm{Cu}$ NPs were collected as an ethanol slurry $(70 \mathrm{wt} \% \mathrm{Cu})$. The slurry was dried under reduced pressure to obtain $\mathrm{Cu}$ $\mathrm{NPs}$ as a powder for characterization. The effect of $\mathrm{NiCl}_{2}$ concentration on $\mathrm{Cu} \mathrm{NP}$ preparation was examined by changing the addition amount of $\mathrm{NiCl}_{2}$ to $0,0.31$, and $1.2 \mathrm{mmol}$ ([metal salt $] /[\mathrm{Cu}]: 0,0.050$, and 0.20 ). To investigate the effect of hydrazine concentration on $\mathrm{Cu} N$ P synthesis, the aqueous solution concentration of $4.85 \mathrm{M}$ hydrazine monohydrate was changed to $1.21 \mathrm{M}, 2.43 \mathrm{M}, 9.7 \mathrm{M}$, and $19.4 \mathrm{M}\left(\left[\mathrm{N}_{2} \mathrm{H}_{4}\right] /[\mathrm{Cu}]: 1.0,2.0,8.0\right.$, and 16).

Preparation of Cu NP-based nanopastes. For the preparation of the $\mathrm{C}_{\mathrm{N}}$ NP-based nanopastes, an ethanol slurry of $\mathbf{C}_{\mathrm{N}}(70 \mathrm{wt} \%)$ was synthesized at a scale 20 times larger than that described above (the stirring time after the addition of the aqueous solution of hydrazine monohydrate was $1 \mathrm{~h}$ ). Then, the resulting slurry was dried in a reduced-pressure atmosphere, and the obtained solid particles were ground with an agate mortar in a $\mathrm{N}_{2}$ atmosphere and sieved to 635 mesh. Next, $\mathrm{C}_{\mathrm{N}}(2.00 \mathrm{~g})$ and triethanolamine $(0.35 \mathrm{~g})$ were mixed in a $\mathrm{N}_{2}$ atmosphere using a rotation-revolution mixer (ARE-310, THINKY CORPORATION) and sieved to 635 mesh. Finally, $0.081 \mathrm{~g}$ methanolic solution of 3-glycidoxypropyltrimethoxysilane (63 $\mathrm{wt} \%$ ) was added to the mixture $(1.00 \mathrm{~g})$ to obtain the $\mathbf{C}_{\mathrm{N}}$-based nanopastes $\left(79 \mathrm{wt} \% \mathbf{C}_{\mathrm{N}}\right)$.

Preparation of Cu NP-based patterned electrodes on glass substrates. The Cu NP-based pastes were printed on a glass substrate $(30 \mathrm{~mm} \times 15 \mathrm{~mm}$, OA-10, Nippon Electric Glass Co., Ltd.) with a size of $20 \mathrm{~mm} \times 10 \mathrm{~mm}$ by screen printing. The thickness of the pastes was adjusted to $55 \mu \mathrm{m}$. Then, the printed glass substrate was pressure-less sintered at $150{ }^{\circ} \mathrm{C}, 180^{\circ} \mathrm{C}, 200^{\circ} \mathrm{C}$, and $260^{\circ} \mathrm{C}$ for 30 min under $\mathrm{N}_{2}$ flow $(1.3 \mathrm{~L} / \mathrm{min})$. The resistivity of the $\mathrm{Cu}$ electrodes obtained by sintering at the different temperatures was measured by a fourpoint probe method.

Fabrication of Cu NP-based patterned electrodes on flexible films. A PEN film (Teonex Q65FA, TEIJIN Ltd., $t=200 \mu \mathrm{m}$ ) and a PET film (DUORA, SEKISUI CHEMICAL CO., LTD., $t=160 \mu \mathrm{m}$ ) were used as the flexible films. Model $\mathrm{Cu}$ electrodes were fabricated on the PEN film by screen printing the $\mathrm{Cu}$ NP-based paste using a screen mask (high-density mesh ST 500, emulsion thickness: $15 \mu \mathrm{m}$, Tokyo Process Service Co., Ltd.) and then sintered at $200^{\circ} \mathrm{C}$ for $30 \mathrm{~min}$ under a $\mathrm{N}_{2}$ flow $(1.3 \mathrm{~L} / \mathrm{min})$. The $\mathrm{Cu}$ electrode on a PET film was prepared using the $\mathrm{Cu}$ NP-based paste by screen printing with a size of $20 \mathrm{~mm} \times 10 \mathrm{~mm}$. Then, the printed film was pressure-less sintered at $150{ }^{\circ} \mathrm{C}$ for 30 min under a $\mathrm{N}_{2}$ flow $(1.3 \mathrm{~L} / \mathrm{min})$ to obtain Cu electrodes on the film.

Preparation of copper-bonded bodies and shear strength measurements. Flat $\mathrm{Cu}$ plates with a clean surface were prepared by rotary polishing oxygen-free $\mathrm{Cu}$ plates (i-ject Co., Ltd., $3 \times 3 \mathrm{~mm}$ and $5 \times 5 \mathrm{~mm}$; $t=1 \mathrm{~mm}$ ) with a manual polishing machine (grit size: \# 4000). Then, the resulting Cu plate $(5 \times 5 \mathrm{~mm})$ on which the $\mathrm{Cu}$ NP-based pastes (1 $\mathrm{mm}$ square) were printed was prepared by screen printing using a metal mask (Tokyo Process Service Co., Ltd.). Then, the $3 \times 3 \mathrm{~mm}$ plate was placed on the printed nanopaste, and the paste was sandwiched between the $\mathrm{Cu}$ plates. The resulting Cu plates were sintered at $200^{\circ} \mathrm{C}$ and $260^{\circ} \mathrm{C}$ for 30 min under pres- 
sure-less conditions with flowing $\mathrm{N}_{2}(1.3 \mathrm{~L} / \mathrm{min})$ for adhesion. The shear strength of the resulting Cu-bonded bodies was measured and calculated by a bond tester (Condor Sigma, XYZTEC) at a shear speed of $50 \mu \mathrm{m} / \mathrm{s}$.

Characterization equipment. X-ray diffraction (XRD) measurements were performed on a Rigaku Intelligent X-ray diffraction SmartLab system equipped with a PILATUS3 R $100 \mathrm{~K}$ detector using CuKa radiation $(40 \mathrm{kV}, 40 \mathrm{~mA})$ to determine the crystal phase and measure crystallite size. Scanning electron microscopy (SEM) observations were carried out using a HITACHI SU 7000 with an acceleration voltage of $5 \mathrm{kV}$. TEM observations were performed using an FEI TITAN 80-300 instrument at $200 \mathrm{kV}$ to obtain HR-TEM and high-angle annular dark field scanning TEM (HAADF-STEM) images. The electrical conductivity of the copper electrodes was measured by a Mitsubishi Chemical Analytech Loresta-GX MCP-T 700 instrument with a four-point probe method. Thermogravimetric analysis (TGA) of the Cu NPs was carried out by a Bruker Japan TG-DTA2000SA at a heating rate of $5{ }^{\circ} \mathrm{C} / \mathrm{min}$ under atmospheric conditions.

Received: 5 October 2021; Accepted: 8 December 2021

Published online: 20 December 2021

\section{References}

1. Kamyshny, A. \& Magdassi, S. Conductive nanomaterials for printed electronics. Small 10, 3515-3535 (2014).

2. Khan, Y. et al. A new frontier of printed electronics: Flexible hybrid electronics. Adv. Mater. 32, 1905279 (2020).

3. Chang, J. S., Facchetti, A. F. \& Reuss, R. A circuits and systems perspective of organic/printed electronics: Review, challenges, and contemporary and emerging design approaches. IEEE J. Emerg. Select. Top. Circuits Syst. 7, 7-26 (2017).

4. Bacalzo, N. P. et al. Controlled microwave-hydrolyzed starch as a stabilizer for green formulation of aqueous gold nanoparticle ink for flexible printed electronics. ACS Appl. Nano Mater. 1, 1247-1256 (2018).

5. Shen, W. F., Zhang, X. P., Huang, Q. J., Xu, Q. S. \& Song, W. J. Preparation of solid silver nanoparticles for inkjet printed flexible electronics with high conductivity. Nanoscale 6, 1622-1628 (2014).

6. Park, S. H. \& Kim, H. S. Flash light sintering of nickel nanoparticles for printed electronics. Thin Solid Films 550, 575-581 (2014).

7. Jo, Y. H., Jung, I., Choi, C. S., Kim, I. \& Lee, H. M. Synthesis and characterization of low temperature Sn nanoparticles for the fabrication of highly conductive ink. Nanotechnology 22, 225701 (2011).

8. Lee, Y. J., Lee, C. \& Lee, H. M. Synthesis of oxide-free aluminum nanoparticles for application to conductive film. Nanotechnology 29, 055602 (2018).

9. Rajan, K. et al. Silver nanoparticle ink technology: State of the art. Nanotechnol. Sci. Appl. 9, 1-13 (2016).

10. Khan, Y. et al. Flexible hybrid electronics: Direct interfacing of soft and hard electronics for wearable health monitoring. Adv. Funct. Mater. 26, 8764-8775 (2016).

11. Matsuhisa, N. et al. Printable elastic conductors by in situ formation of silver nanoparticles from silver flakes. Nat. Mater. 16, 834-840 (2017).

12. Li, X. T., Andersson, H., Siden, J. \& Schon, T. Soldering surface mount components on screen-printed Ag patterns on paper and polyimide substrates for hybrid printed electronics. Flex. Print. Electron. 3, 015003 (2018).

13. Zhang, Z. et al. Pressureless and low-temperature sinter-joining on bare Si, SiC and GaN by a Ag flake paste. Scr. Mater. 198, 113833 (2021).

14. Kim, D. et al. Fracture mechanism of microporous Ag-sintered joint in a GaN power device with Ti/Ag and Ni/Ti/Ag metallization layer at different thermo-mechanical stresses. J. Mater. Sci. 56, 9852-9870 (2021).

15. Zhang, H. W., Minter, J. \& Lee, N. C. A brief review on high-temperature, Pb-free die-attach materials. J. Electron. Mater. 48, 201-210 (2019).

16. Lee, H., Smet, V. \& Tummala, R. A review of SiC power module packaging technologies: Challenges, advances, and emerging issues. IEEE J. Emerg. Select. Top. Power Electron. 8, 239-255 (2020).

17. Gao, Y. et al. Reliability analysis of sintered $\mathrm{Cu}$ joints for $\mathrm{SiC}$ power devices under thermal shock condition. Microelectron. Reliab. 100, 113456 (2019).

18. Yoon, J. W. \& Back, J. H. Effect of sintering conditions on the mechanical strength of Cu-sintered joints for high-power applications. Materials 11, 2105 (2018).

19. Kwon, J. et al. Low-temperature oxidation-free selective laser sintering of $\mathrm{Cu}$ nanoparticle paste on a polymer substrate for the flexible touch panel applications. ACS Appl. Mater. Interfaces 8, 11575-11582 (2016).

20. Del Carro, L. et al. Oxide-free copper pastes for the attachment of large-area power devices. J. Electron. Mater. 48, 6823-6834 (2019).

21. Jeong, S. et al. Air-stable, surface-oxide free $\mathrm{Cu}$ nanoparticles for highly conductive $\mathrm{Cu}$ ink and their application to printed graphene transistors. J. Mater. Chem. C 1, 2704-2710 (2013).

22. Ryu, C. H., Joo, S. J. \& Kim, H. S. Intense pulsed light sintering of Cu nano particles/micro particles-ink assisted with heating and vacuum holding of substrate for warpage free printed electronic circuit. Thin Solid Films 675, 23-33 (2019).

23. Hernandez-Castaneda, J. C., Lok, B. K. \& Zheng, H. Y. Laser sintering of Cu nanoparticles on PET polymer substrate for printed electronics at different wavelengths and process conditions. Front. Mech. Eng. 15, 303-318 (2020).

24. Gao, Y. et al. Fabrication of a flexible copper pattern based on a sub-micro copper paste by a low temperature plasma technique. RSC Adv. 5, 90202-90208 (2015).

25. Ishizaki, T. \& Watanabe, R. A new one-pot method for the synthesis of Cu nanoparticles for low temperature bonding. J. Mater. Chem. 22, 25198-25206 (2012)

26. Oliva-Puigdomenech, A., De Roo, J., Van Avermaet, H., De Buysser, K. \& Hens, Z. Scalable approaches to copper nanocrystal synthesis under ambient conditions for printed electronics. ACS Appl. Nano Mater. 3, 3523-3531 (2020).

27. Deng, D. Y., Jin, Y. X., Cheng, Y. R., Qi, T. K. \& Xiao, F. Copper nanoparticles: Aqueous phase synthesis and conductive films fabrication at low sintering temperature. ACS Appl. Mater. Interfaces. 5, 3839-3846 (2013).

28. Hokita, Y., Kanzaki, M., Sugiyama, T., Arakawa, R. \& Kawasaki, H. High-concentration synthesis of sub-10-nm copper nanoparticles for application to conductive nanoinks. ACS Appl. Mater. Interfaces 7, 19382-19389 (2015).

29. Mou, Y., Liu, J. X., Cheng, H., Peng, Y. \& Chen, M. X. Facile preparation of self-reducible Cu nanoparticle paste for low temperature $\mathrm{Cu}-\mathrm{Cu}$ bonding. JOM 71, 3076-3083 (2019).

30. Kamikoriyama, Y., Imamura, H., Muramatsu, A. \& Kanie, K. Ambient aqueous-phase synthesis of copper nanoparticles and nanopastes with low-temperature sintering and ultra-high bonding abilities. Sci. Rep. 9, 899 (2019).

31. Sugimoto, T. Formation of monodispersed nano- and micro-particles controlled in size, shape, and internal structure. Chem. Eng. Technol. 26, 313-321 (2003).

32. Sugimoto, T., Itoh, H. \& Mochida, T. Shape control of monodisperse hematite particles by organic additives in the gel-sol system. J. Colloid Interface Sci. 205, 42-52 (1998). 
33. Sugimoto, T., Dirige, G. E. \& Muramatsu, A. Synthesis of monodisperse CdS and ZnS particles from concentrated solutions of the EDTA-metal complexes. J. Colloid Interface Sci. 180, 305-308 (1996).

34. Kanie, K. \& Sugimoto, T. Shape control of anatase TiO2 nanoparticles by amino acids in a gel-sol system. Chem. Commun. 14, $1584-1585$ (2004).

35. Suzuki, R., Nishi, Y., Matsubara, M., Muramatsu, A. \& Kanie, K. Single-crystalline protrusion-rich indium tin oxide nanoparticles with colloidal stability in water for use in sustainable coatings. ACS Appl. Nano Mater. 3, 4870-4879 (2020).

36. Nishi, Y. et al. Gallium-doped zinc oxide nanoparticle thin films as transparent electrode materials with high conductivity. ACS Appl. Nano Mater. 3, 9622-9632 (2020).

37. Koubu, H. et al. Synthesis of noble metal-doped Cu nanoparticles by ultrasonication. Mater. Trans. 54, 1496-1501 (2013).

38. Ramamoorthy, R. K. et al. One-pot seed-mediated growth of Co nanoparticles by the polyol process: Unraveling the heterogeneous nucleation. Nano Lett. 19, 9160-9169 (2019).

39. Sivaranjani, K. S., Jacob, G. A. \& Joseyphus, R. J. Coercivity and exchange bias in size reduced iron obtained through chemical reduction. J. Magn. Magn. Mater. 513, 167228 (2020).

40. Sugimoto, T. Monodispersed Particles 2nd edn. (Elsevier, 2019).

41. Muramatsu, A. \& Sugimoto, T. Synthesis of uniform spherical Cu2O particles from condensed CuO suspensions. J. Colloid Interface Sci. 189, 167-173 (1997).

42. Kobayashi, Y., Abe, Y., Maeda, T., Yasuda, Y. \& Morita, T. A metal-metal bonding process using metallic copper nanoparticles produced by reduction of copper oxide nanoparticles. J. Market. Res. Technol. 3, 114-121 (2014).

43. Patterson, A. L. The Scherrer formula for X-ray particle size determination. Phys. Rev. 56, 978-982 (1939).

44. Rumble, J. R., Bruno, T. J. \& Doa, M. J. CRC Handbook of Chemistry and Physics: A Ready-Reference Book of Chemical and Physical Data (CRC Press/Taylor \& Francis Group, 2021).

45. Suzuki, R., Nishi, Y., Matsubara, M., Muramatsu, A. \& Kanie, K. A nanoparticle-mist deposition method: Fabrication of highperformance ITO flexible thin films under atmospheric conditions. Sci. Rep. 11, 10584 (2021).

\section{Acknowledgements}

The authors thank Mr. Y. Inagaki of Mitsui Mining \& Smelting Co., Ltd. for the synthesis and characterization of $\mathrm{Cu}$ NPs. We also thank Dr. Y. Hayasaka of Tohoku University for the observation of Cu NPs by HR-TEM. This work is partly supported by NEDO Feasibility Study Program (No. 19II0101X).

\section{Author contributions}

H.I., Y.K., A.M. and K.K. conceived the experiments; H.I., Y.K. and K.K. synthesized and characterized the copper NPs, conducted the experiments, and analyzed the results. H.I. and Y.K. prepared the Cu nanopastes and characterized the properties. The manuscript was prepared by H.I., Y.K. and K.K. All authors edited the manuscript.

\section{Competing interests}

The authors declare no competing interests.

Additional information

Correspondence and requests for materials should be addressed to H.I. or K.K.

Reprints and permissions information is available at www.nature.com/reprints.

Publisher's note Springer Nature remains neutral with regard to jurisdictional claims in published maps and institutional affiliations.

(c) (i) Open Access This article is licensed under a Creative Commons Attribution 4.0 International License, which permits use, sharing, adaptation, distribution and reproduction in any medium or format, as long as you give appropriate credit to the original author(s) and the source, provide a link to the Creative Commons licence, and indicate if changes were made. The images or other third party material in this article are included in the article's Creative Commons licence, unless indicated otherwise in a credit line to the material. If material is not included in the article's Creative Commons licence and your intended use is not permitted by statutory regulation or exceeds the permitted use, you will need to obtain permission directly from the copyright holder. To view a copy of this licence, visit http://creativecommons.org/licenses/by/4.0/.

(c) The Author(s) 2021 